\title{
COMPLIMENT STRATEGIES PRODUCED BY EFL LEARNERS OF ENGLISH STUDY PROGRAM IN RIAU, INDONESIA
}

\author{
Lili Ariani $^{1}$, Indah Tri Purwanti ${ }^{2}$, Eliwarti ${ }^{3}$ \\ ${ }^{1,2,3}$ Faculty of Teachers Training and Education \\ Universitas Riau
}

Corresponding author: indah.tri@lecturer.unri.ac.id

\begin{tabular}{ll}
\hline \multicolumn{1}{c}{ Article Info } & Abstract \\
\hline $\begin{array}{l}\text { Received: 12 June 2021 } \\
\text { Accepted: 02 October 2021 } \\
\text { Published: 26 October 2021 }\end{array}$ & $\begin{array}{l}\text { This research was aimed at analysing students' strategies in giving } \\
\text { compliments. This was descriptive qualitative research using a } \\
\text { qualitative approach accompanied by descriptive statistics. This } \\
\text { research involved 39 EFL students as the participants in the academic } \\
\text { year 2019/2020 selected using cluster random sampling technique. The } \\
\text { instrument used to collect the data was a DCT (Discourse Completion } \\
\text { Keywords: }\end{array}$ \\
$\begin{array}{l}\text { Test) containing several situations where the students were expected to } \\
\text { give their compliments. The result showed that the students used many }\end{array}$ \\
$\begin{array}{l}\text { knbound semantic formula; } \\
\text { bound semantic formula; } \\
\text { explicit compliment; } \\
\text { implicit compliment }\end{array}$ & $\begin{array}{l}\text { most used by the students. Furthermore, the single explicit strategy } \\
\text { appeared the most within overall strategies that appeared in the DCT. } \\
\text { This implied that the students prefer to give a direct and simple } \\
\text { compliment. One strategy in giving compliments appeared out of the } \\
\text { classification which is congratulation attached to an unbound semantic } \\
\text { formula. }\end{array}$
\end{tabular}

\section{INTRODUCTION}

A compliment is one speech act that people perform to give praise or to show their admiration. Holmes (1986, as cited in Dirgeyasa, 2015) defines compliment as a positive evaluation valued explicitly or implicitly given by the speaker to someone (addressee) usually for good such as possession, characteristic, skill, etc. and is affective to maintain solidarity. Besides maintaining solidarity, compliment is a speech act that is aimed at improving or supporting the addressee's face in their interaction (Goffman, 1967, as cited in Bruti, 2008). This speech acts also as 'social lubricant' to grease the social wheels (Wolfson, 1983, as cited in Zhang, 2013). The function of compliment is more affective rather than referential. It means the compliment is a strategy used as a social lubricant to establish common ground, mutuality or maintain social solidarity (Al-Azzawi, 2011).

\section{International Journal of Educational Best Practices (IJEBP)}

Vol. 5 No. 2 October 2021

ISSN: $2581-0847$

DOI: 10.32851/ijebp.v5n2.p132-152 
The sums from some experts regarding to the function of compliments that compliments have six functions (Wu, 2008, as in Dirgeyasa, 2015). First, show admiration or approval of someone's work, taste, and appearance. When a speaker says, "I like you mobile phone", he shows his admiration of the addressee's possession and gives a praise (Herbert, 1990). Second, establish, confirm or to maintain solidarity. For example, when someone who is a stranger comes into a group says, "I like your dress", it can be regarded as a method or strategy in communication to establish the rapport of the group (Walfson, 1983). Third, it is used to replace gratitude, congratulations, greetings, and apologies. The sentence "How nice you are today" can be functioned as "How are you" when two friends meet (Walfson, 1983). Fourth, soften a face-threatening act such as apologies, requests, and criticisms. Apologies, request, and criticism can cause a face-threatening act toward the addressee. The speaker can give compliments to avoid a strong face-threatening in communication (Walfson, 1983). Fifth, as a conversational strategy. A compliment can be used to open and sustain conversation. In the sentence "Hi, you English is very good, when did you begin to learn?" If the interlocutors are strangers, they can begin their conversation by using compliment (Walfson, 1983). Sixth, reinforce desired behaviour. The speaker uses compliment to show his strong hope besides showing admiration. For example, in "How nice your earrings are! Where did you buy them?" The speaker does not only express his admiration for the earrings but also has a strong hope to have or to buy the same earrings (Maner, 1983).

Different cultures have their own system in giving compliments, not only the formulation utilized but also their frequency of occurrence, the context where they were expected to be appropriate, the responses from the addressee, how the utterance is recognized as a compliment and the function of the speech act performed (Garcia, 2018). In general, compliments are presented as positive politeness strategies, because they indicate that the complimenter notices or attends to the addressee's face desires (Farenkia, 2012). The compliment positive interpretation depends on how flourishing the speaker weighs the specific situation, linguistic and socio-cultural (gender, social, distance, power distance, setting, linguistic forms, topic, etc.) on the other side, compliment may threaten the face of the involved people (has such as hidden intention, are not sincere, exaggerated, represents an intrusion to the private sphere or compel the addressee to share complimented object with the speaker) may then provoke the negative reaction (Farenkia, 2012). In line with this statement, Bhatti and Zegarac (2012) say that a compliment may give a threat to the addressee's negative face easily. In some cultures, a compliment toward someone's personal possessions is usually interpreted as an expression of the complimenter's desire to have the hearer's complimented object and put the hearer under a social responsibility to give it to the speaker as a present.

In Dastjerdi \& Farshid (2011), the formula of compliments provided the first comprehensive description of American English. They found that the majority of observed compliments accounted for a narrow range of syntactic formulas with the majority (97.2\%) of their corpus of 686 naturally occurring compliments falling into one of the following nine syntactic formulas: 
1. NP is/looks (really) ADJ (Your hair looks nice)

2. I (really) like/love NP (I love your hair.)

3. PRO is (really) (a) ADJ NP (This was really a great meal.)

4. You V (a) (really) ADJ NP (You did a good job.)

5. You V (NP) (really) ADV (You really handled that situation well.)

6. You have (a) (really) ADJ NP! (You have such beautiful hair!)

7. What (a) ADJ NP! (What a lovely baby you have!)

8. ADJ NP! (Nice game!)

9. Isn't NP ADJ! (Isn't your ring beautiful!)

(Wolfson and Menes, 1980, as cited in Dastjerdi \& Farshid, 2011, p. 461)

Although the list may be somewhat dated and may differ for varieties of English, the common adjectives used in giving compliments according to Wolfson and Manes (1981, as cited in Ishihara, 2010) are nice, good, pretty, great, and beautiful.

In a study conducted by Yuan (2002), the compliment semantic formula is divided into 2 major categories which are Compliments and Non-Compliment Replies. Compliments are further divided into two categories which are unbound semantic formulas and bound semantic formulas. Unbound semantic formula means the expression that can be interpreted as a compliment. It is divided into two strategies which are explicit compliment strategy with at least one positive semantic carrier and implicit compliment strategy with no positive semantic carrier but indicates positive meaning. The bound semantic formula is the expression that has to be attached with one of the unbound semantic formulas to be interpreted as a compliment. It consists of six categories which are explanation, information question, request, contrast, advice, and future reference. The other category is a non-Compliment which means bound semantic strategy that does not carry any positive meaning.

This research is aimed at investigating and providing the analysis for the compliment's strategies produced by the EFL students in English Study Program in Universitas Riau including the combinations and the characteristics of their compliment as EFL students. Based on the daily observation, the students rarely compliment to each other. In a situation where they are expected to give a compliment, they tend to use the same expression or word choice such as 'nice' and 'good', for example when they were asked to give feedback for their classmate's performance and they used mostly the same rule and expression such as "I like your presentation", "The performance is good", or "Your pronunciation is good". In this research, the researcher wants to provide a more possible situation in order to see the students' strategies in giving compliments. 


\section{METHODOLOGY}

This study involved 39 sixth-semester students of English Education Department of Universitas Riau in the academic year 2019/2020 selected by using cluster random sampling technique. The participants were asked to fill the written task to see their compliment strategies. The compliment strategies were collected by using DCT (Discourse Completion Task) distributed to the participant.

The DCT is an instrument that contains several hypothetical situations where the participants were expected to respond to the given situation. In this research, the DCT was adapted from Dastjerdi and Farshid (2011). The DCT for this research contained 9 situations of three topics. The topics of the situation were possession (3 items), appearance (3 items), and skill or ability (3 items). The DCT was distributed to the students by using Google Docs.

The answers collected from DCT were classified into certain compliment strategies as followed.

1. Compliment

a. Unbound Semantic Formula

$>$ Explicit Compliment

$>$ Implicit Compliment

b. Bound Semantic Formula

$>$ Explanation

$>$ Information Question

$>$ Future Reference

$>$ Advice

$>$ Request

$>$ Contrast

2. Non-Compliment

$>$ Non-compliment

$>$ Opt. Out

(Yuan, 2002 p.192)

In the collected data, the supporting theory was needed to be classified the utterances because they were out of the strategy proposed by Yuan (2002). Those expressions such as pre-compliment, wish expression were from Farenkia (2012). There is a strategy that is used in giving compliments out of the two compliment strategies proposed by Yuan (2002) and Farenkia (2012) which is congratulation.

The classified utterances produced by the participants were grouped based on some single strategy and combinations. To see which strategy the participant frequently used, a simple statistic was done. 


\section{FINDINGS}

\section{A. The strategies produced by the students}

Six strategies were found used in giving compliments as followed; single unbound semantic formula, the combination of unbound-bound semantic formula, the combination of unbound-pre-compliment and/or wish expression, the combination of unboundbound-pre-compliment/wish expression, the combination of non-compliment-unbound semantic formula, and non-compliment. The single unbound semantic formula appeared to be the most produced strategy by 255 occurrences or $72,65 \%$ of 351 responses.

\section{Single unbound semantic formula}

Single unbound semantic formula is divided into explicit and implicit compliments that only appeared by them self. Single explicit compliment means the utterance that contains at least one positive semantic carrier to be coded as a compliment and appears only itself without any combination with bound semantic formula. Implicit compliment contains no positive semantic carrier but indicates positive meaning (Yuan, 2002). The single unbound semantic formula implies that the participants prefer to say their compliments simply without combinations. The following are the expressions produced by the participants in responding to the given situations.

\section{a. Single explicit strategy}

The participants frequently used a single explicit strategy in their responses. Instances of their single explicit strategy can be viewed as in the following:

(1) S1: 'Wow, your phone is sophisticated!'

(2) S4: 'You've got a good sense of style'

(3) S5: 'You look great in that clothes'

The compliment (1), (2), and (3) contain 'sophisticated', 'good', and 'great' as positive semantic carriers and have no combination. As it has a positive semantic carrier and has no combination, the compliments are classified as a single explicit strategy.

\section{b. Single implicit strategy}

Some single implicit compliments were found as the responses of the participants to the given situation. Instances of their single implicit strategy can be viewed as in the following:

(4) S10: 'Wow, I think I can hear your voice everyday'

(5) S7: 'Two thumbs up for you'

(6) S21: 'You really like a teacher 
The compliment (4) has no positive semantic carrier, but positive meaning can be inferred. The participants do not say that the addressee has a good voice directly, but people only want to hear someone with a good voice sing every day. The sentence (5) has no positive semantic carries but indicates the positive meaning as 'you did a great job' so it is classified as an implicit compliment. There is also no positive semantic carrier in sentence number (6), but it implies positive meaning that the addressee can give a good and understandable explanation.

The frequency and percentage of this strategy are presented in table 1.

Table 1. Single Bound Semantic Formula

\begin{tabular}{lccc}
\hline No. & Unbound Semantic Formula & Frequency & Percentage \\
\hline 1. & Single Explicit Strategy & 252 & $71,80 \%$ \\
2. & Single Implicit Strategy & 3 & $0,85 \%$ \\
\hline & TOTAL & $\mathbf{2 5 5}$ & $\mathbf{7 2 , 6 5 \%}$ \\
\hline
\end{tabular}

The table above shows the different frequency between the single explicit and single implicit strategies produced by the participants. It seems like the participants prefer to express their admiration simply and directly rather than saying it indirectly.

\section{The combination of unbound-bound semantic formula}

In this category, unbound semantic formulas (explicit or implicit) appeared with one or more bound semantic formulas such as explanation, information question, future reference, advice, and request. There are 9 forms of combinations as followed:

\section{a. Explicit - explanation}

Explicit - explanation is the most used strategy in the category of unbound - bound semantic formula. In this strategy, explicit compliments appeared with additional sentences that support the compliment given. The use of this strategy can be viewed as the following:

(7) S1: 'You doing good! I am amazed on how you finish your presentation!'

(8) S3: 'I like your voice; it sounds like professional singer'

(9) S12: 'That was a great presentation! I particularly liked the funny examples you used'

The example numbers (7), (8), and (9) contain positive semantic carriers such as 'good', 'like', and 'great' so they are classified as explicit compliments. The sentence after an explicit compliment is the explanation used to tell what makes them amazed. For example, the sentence 'I am amazed on how you finish your presentation!' explains that the way the addressee delivers the explanation and finishes the

\section{International Journal of Educational Best Practices (IJEBP)}

Vol. 5 No. 2 October 2021

ISSN: $2581-0847$

DOI: $10.32851 /$ ijebp.v5n2.p132-152 
presentation amazes the complimenter. The same goes with the sentence 'it sounds like professional singer' tell that the addressee's voice sounds good as a real singer so the complimenter. 'I particularly liked the funny examples you used' explains why the complimenter praise the presentation.

\section{b. Explicit - information question}

This strategy contains the combination of explicit compliments accompanied with questions for more information related to the things being complimented. The use of this strategy can be viewed as the following:

(10)S04: 'Hey Michael, nice shoes. Are those your new shoes?'

(11)S13: 'Your cell phone is so sophisticated. Where did you buy it?'

(12) S14: 'I love your unique hairstyle; do you make it by yourself?'

The example (10), (11) and (12) contain the words 'nice', 'sophisticated', and 'unique' as the positive semantic carriers to be coded as explicit compliments. These compliments are followed by the questions used by the complimenter to ask the addressee for more information such as in example (10) 'Are those your new shoes?', example (11) 'Where did you buy it?', example (12) and 'do you make it by yourself?'.

\section{c. Explicit - Future Reference}

Explicit - future question is a combination where explicit compliment accompanied with a sentence that refers to what will happen in the future. The use of this strategy can be viewed as the following:

(13)S28: 'Nice suit, Aldi. You will be accepted for sure!'

(14)S14: 'The suit looks stunning, you'll be very handsome when you wear it.'

The words 'Nice' and 'stunning' are positive semantic carries and are followed by the sentence talking about what will happen in the future so (13) and (14) are classified as explicit - future reference strategy.

\section{d. Explicit - advice}

This is a combination of explicit compliment with the offered opinion or suggestion about what the addressee should do or act. The use of this strategy can be viewed as the following:

(15)S27: 'What a great mark! you should be proud of yourself!'

(16) S6: 'You doing it very well, you should surprise us again in the next presentation'

The words 'great' and 'well' are the positive semantic carriers that give positive evaluation. The compliments are followed by the sentences that deliver suggestions 
after the compliment such as 'you should be proud of yourself!' in (15) and 'you should surprise us again in the next presentation' in (16).

\section{e. Explicit - request}

In this combination, besides giving a compliment, the complimenter also asks the addressee to do something. The use of this strategy can be viewed as the following:

(17) S2: 'Awesome, can i give it a look?'

(18)S2: 'Thats amazing! maybe you can tutor me'

(19)S19: 'Well done bro, I think you should teach me how to present a good presentation'

The words 'awesome', 'amazing', and 'well done' are the positive semantic carriers that bring the positive meaning or evaluation, so they are coded as explicit compliments. The rest of the sentences are coded as requested because the complimenter asks something to the addressee. In (17) the complimenter wants to see the phone closely because it is an awesome new phone. In examples (18) and (19) the complimenter asks the addressee to teach the complimenter.

\section{f. Implicit - explanation}

This strategy is the combination of implicit compliment that has no positive semantic carrier with an explanation that supports the compliment. The use of this strategy can be viewed as the following:

(20)S8: 'I thought I was listening to an angel, it turns out it was your voice that sounded angelic.'

The sentence 'I thought I was listening to an angel' does not contain any positive semantic carrier but it implicitly says that the addressee has a nice voice. The complimenter later says that it is because the voice sounds angelic.

\section{g. Explicit - information question - explanation}

There is only one response found for this strategy as in the following:

(21)S11: 'Look at you and your stylish hair. Must have gone to a good salon huh? I mean you always do never spare anything to be fashionable'

The explicit compliment is the sentence 'Look at you and your stylish hair' because it contains the word 'stylish' as the positive semantic carrier. 'Must have gone to a good salon huh' is coded as an information question and the sentence 'I mean you always do never spare anything to be fashionable' is coded as an explanation. 


\section{h. Explicit - information question - future reference}

There is only one response found for this strategy as in the following:

(22) S23: 'Is it you new bag? It's so beautiful. I like it, anytime i'll ask my mother to buy it for me.'

The sentence 'It's so beautiful. I like it,' that contains positive semantic carriers 'beautiful'. The question 'Is it you new bag?' is coded as an information question and the sentence 'anytime i'll ask my mother to buy it for me.' Is coded as a future reference since the complimenter tells about something he/she will do in the future.

\section{i. Explicit - Information Question - Request}

There is only one respond found for this strategy as in the following:

(23)S11: 'You always give such interesting and easy to understand presentation. Is there a secret? Is there a secret?

The word 'interesting' and 'easy' are positive semantic carriers so the sentences are coded as explicit compliments. The complimenter later asks about the secret of being able to give a good presentation by asking 'Is there a secret?'. The complimenter also requests for the addressee to tell the tips on how to do such an interesting presentation by saying 'Is there a secret? .

The frequency and percentage of this strategy are presented in the Table 2 below:

Table 2. Unbound - bound semantic formula

\begin{tabular}{clcc}
\hline No & Compliment Strategies & Frequency & Percentage \\
\hline 1. & Explicit - Explanation & 36 & $10,26 \%$ \\
2. & Explicit - Information Question & 24 & $6,84 \%$ \\
3. & Explicit - Future Reference & 2 & $0,57 \%$ \\
4. & Explicit - Advice & 2 & $0,57 \%$ \\
5. & Explicit - Request & 3 & $0,85 \%$ \\
6. & Implicit - Explanation & 1 & $0,28 \%$ \\
7. & Explicit - Information Question - & 1 & $0,28 \%$ \\
& Explanation & 1 & $0,28 \%$ \\
8. & Explicit - Information Question - Future & & $0,28 \%$ \\
& Reference & 1 & $\mathbf{2 0 , 2 2 \%}$ \\
9. & Explicit - Information Question - Request & $\mathbf{7 1}$ & \\
\hline
\end{tabular}

From the table above, the combination of explicit with explanation is the most used strategy among the combinations of unbound and bound semantic formulas with 36 
occurrences or $10.26 \%$ followed by the combination of explicit - information questions with 24 occurrences or $6.84 \%$.

\section{The Combination of Unbound - Pre-compliment and/or Wish expression}

In this category, there are 3 forms of combination of unbound and pre-compliment and/or wish expression. The combination of unbound semantic formula and wish expression is the most produced strategy among the three strategies in this category. The use of this strategy can be viewed as the following:

\section{a. Pre-compliment-explicit}

The use of this strategy can be viewed as the following:

(24)S1: 'You got the new one! That's awesome!'

The sentence 'You got the new one!' is coded as a pre-compliment because it doesn't contain any positive semantic carrier nor inferred any positive meaning. It also doesn't belong to any bound semantic formula. The sentences are used as a conversation opener before giving the compliment. 'That's awesome!' is coded as an explicit compliment because it has 'awesome' as the positive semantic carrier.

\section{b. Explicit- wish expression}

This is a combination of explicit compliments with wish expressions. Wish expression contains complimenter wish something good for the addressee or to wish the same thing as the addressee (stuff, or skill)

(25)S1: 'You looks so good on that suit! Hope the interview runs well!'

(26)S2: 'You look good Aldi! break a leg'

(27)S3: 'Good job farhan, I hope I also get A'

Examples (25), (26) and (27) use the word 'good' as the positive semantic carrier so they are coded as explicit compliments. Example numbers (25) and (25) are wish expressions where the complimenter wishes for a good thing to the addressee. The phrase 'break a leg' is a slang version of 'good luck'. In example (27) the complimenter use wish expression that she/he wants to have a good score.

\section{c. Pre-compliment-implicit}

(28)S11: 'Wow, you really look the part there. You can definitely get the job if you keep up that appearance.' 
The sentences 'Wow, you really look the part there.' is classified as a pre-compliment because it has no positive semantic carrier. It doesn't infer any positive meaning and doesn't belong to any of the bound semantic formulas. The sentence 'You can definitely get the job if you keep up that appearance.' Is coded as an implicit compliment because there is no positive semantic carrier, but it has a positive meaning. The complimenter doesn't say that the addressee's appearance is good directly but implicitly gives admiration by saying that the addressee can get the job with that appearance.

The frequency and percentage of this strategy are presented in the table below:

Table.3 Unbound - Pre-compliment and/or Wish Expression

\begin{tabular}{llcc}
\hline No. & Compliment Strategy & Frequency & Percentage \\
\hline 1. & Pre-compliment - Explicit & 2 & $0,57 \%$ \\
2. & Explicit - Wish Expression & 9 & $2,56 \%$ \\
3. & Pre-compliment - Implicit & 1 & $0,28 \%$ \\
\hline & TOTAL & $\mathbf{1 2}$ & $\mathbf{3 , 4 2 \%}$ \\
\hline
\end{tabular}

The table shows that the participants combine wish expression slightly more frequently than pre-compliment with 9 occurrences or $2,6 \%$ out of the total 351 compliments.

\section{The combination of unbound-bound-pre-compliment and/or wish expression}

In this category, there are 2 forms of combination of unbound with bound and precompliment and/or wish expression. The use of this strategy can be viewed as the following:

\section{a. Explicit - information question-wish expression}

(29) S11: 'Nice shoes you have there. I also want something cool like that. where did you buy it?'

The The word 'nice' is the positive semantic carrier in the example (29) so the sentence 'Nice shoes you have there' is coded as an explicit compliment. The sentence 'I also want something cool like that' is coded as a wish expression that expresses the complimenter's wish to have the same nice shoes. The complimenter asks for more information related to the shoes by asking 'where did you buy it?', so it is classified as an information question.

\section{b. Pre-Compliment - Explicit - Request}

(30)S11: 'Hey, you got a new phone. Must be so nice to have a new one. Can I see it for a second? I wanna see how cool it is.' 
The compliment is started with a pre-compliment in the sentence 'Hey, you got a new phone' since it has no positive semantic carries and does not carry any positive meaning. It is also not one of the bound semantic formulas. The sentence 'Must be so nice to have a new one' has the word 'nice' as the positive semantic carrier so it is classified as an explicit compliment.

The frequency and percentage of this strategy are presented in the table below:

Table.4 Unbound - Bound - Pre-compliment and/or wish expression

\begin{tabular}{llcc}
\hline No. & Compliment Strategy & Frequency & $\begin{array}{c}\text { Percen } \\
\text { tage }\end{array}$ \\
\hline 1. & Explicit - Information Question - Wish Expression & 2 & $0,57 \%$ \\
2. & Pre-Compliment - Explicit - Request & 1 & $0,28 \%$ \\
\hline & TOTAL & $\mathbf{3}$ & $\mathbf{0 , 8 5 \%}$ \\
\hline
\end{tabular}

\section{The combination of non-compliment and unbound semantic formula $(1,14 \%)$}

The frequency of this combination is 4 occurrences or $1,14 \%$ of the total 351 data. The non-compliment in this combination is only congratulation that appeared with unbound semantic formula only in situation number 9. The use of this strategy can be viewed as the following:

(31) Wow! you doing great! Congratulations! (S-1)

(32) Congratulation. I am so proud of you. (S-16)

(33) Congratulation Farhan. Your efforts yielded amazing results ( $S-31)$

(34) Congratulations!! Your efforts yielded amazing result (S-34)

The word 'congratulation' is a non-compliment that appears with an explicit compliment. The example (31) has 'great' as the positive semantic carrier so the sentence 'Wow! you doing great!' is coded as an explicit compliment. The same goes to number (23) with the word 'proud' as a positive semantic carrier, numbers (33) and (34) with the word 'amazing' as a positive semantic carrier so they are coded as explicit compliments.

\section{Non-compliment}

Non-compliments are either bound semantic formulas occurring by themselves or other replies that do not carry any positive meanings (Yuan, 2002). In this research, there are several data classified as non-compliment because they were not attached with any unbound semantic formula and did not carry any positive meaning. In this study, 6 noncompliments or $1,7 \%$ found out of 351 data of compliments. The use of this strategy can be viewed as the following:

(35) Ohh you got a new phone! When did you buy it? 
(36) Goodluck brother!

(37) Yuhuuuuu can I borrow your camera phone for take a selfie? Hehhe

The frequency and percentage of all the strategies are presented in the table below:

Table 5. The Compliment Strategies

\begin{tabular}{|c|c|c|c|}
\hline No. & Compliment Strategies & Frequency & Percentage \\
\hline 1. & Single Unbound Semantic Formula & 255 & $72,65 \%$ \\
\hline 2. & $\begin{array}{l}\text { The Combination of Unbound - Bound Semantic } \\
\text { Formula }\end{array}$ & 71 & $20,2 \%$ \\
\hline 3. & $\begin{array}{l}\text { The Combination of Unbound - Pre-Compliment } \\
\text { and/or Wish Expression }\end{array}$ & 12 & $3,4 \%$ \\
\hline 4. & $\begin{array}{l}\text { The Combination of Unbound - Bound - Pre- } \\
\text { Compliment and/or Wish Expression }\end{array}$ & 3 & $0,8 \%$ \\
\hline 5. & $\begin{array}{l}\text { The Combination of Non-Compliment and } \\
\text { Unbound Semantic Formula }\end{array}$ & 4 & $1,1 \%$ \\
\hline 6. & Non-Compliment. & 6 & $1,7 \%$ \\
\hline & TOTAL & 351 & $100 \%$ \\
\hline
\end{tabular}

The table shows that the participants mostly use the single unbound semantic formula rather than other strategies. It may indicate that the participant prefers to give their praise in a simple way to show their admiration. The frequency of Single Unbound Semantic Formula is the highest among the others with 255 or $72,65 \%$ out of 351 compliments.

Here are the three most-produced compliments strategies by the participants.

\section{a. Single explicit compliment}

The single explicit compliment is a strategy that directly shows the complimenter's admiration with at least one positive semantic carrier. This strategy got the highest percentage which is $71,80 \%$ or 252 data of compliments from the total of 351 data.

\section{b. Explicit - explanation}

This is a combination of an unbound semantic formula (explicit) and a bound semantic formula (explanation) where the complimenter adds more sentences to explain the things being complimented. The percentage of this strategy is $10,26 \%$. This strategy is the most used combination among all the combinations with unbound semantic formulas gained in this research. 


\section{c. Explicit - information question}

Explicit - information question is a combination where the compliments besides giving their praise, also like to ask for more information related to what they compliment. For example, the students ask their friend when she buys a nice bag. The students as the complimenter not only admire the bag but also want to know where to buy it so they ask their friend for more information about the bag so they can buy it as well. This strategy is the second combination after that used the most by the students with the percentage being $6,84 \%$.

Table 6. The Most-Produced Strategies

\begin{tabular}{clcc}
\hline No. & \multicolumn{1}{c}{ Compliment Strategy } & Frequency & Percentage \\
\hline 1. & Single Explicit & 252 & $71,80 \%$ \\
2. & Explicit - Explanation & 36 & $10,26 \%$ \\
3. & Explicit - Information Question & 24 & $6,84 \%$ \\
\hline & TOTAL & $\mathbf{3 1 2}$ & $\mathbf{8 8 , 9 0 \%}$ \\
\hline
\end{tabular}

The table shows three most used strategies involving explicit strategy that implied in showing their admiration and praise, the participants prefer to express the compliment directly. Single explicit appeared to be the most used strategy because its frequency of occurrence is the highest among other strategies. It can be assumed that the participants like to give compliments directly and simply. The following strategies are explicit - explanation, and explicit - information question as the most used combination. The use of explanation and information questions indicate that besides directly saying compliment, the participants also like to add more expression to support their compliment and also like to gain more information about the things being complimented

\section{The characteristics of the compliment and first language (L1) influence}

Some characteristics of giving compliments by the participants are noticed. In giving a compliment, the way the participants express their admiration is divided into two ways on each topic. First, on the topic of possession, it is found that the participants frequently give compliments on the object rather than using ' $T$ ' as the subject. For example, it is more common to find them saying 'That a nice shoes, Michael' rather than 'I like your shoes, very beautiful.'. Second, on the topic of appearance, the participants also like to give compliments on the addressee rather than using ' $I$ ' as the subject. For example, the participants prefer to say 'You look beautiful with that hair style!' to compliment the addressee rather than saying 'I like your hair style!'. Third, on the topic of skill or ability, the participants frequently give compliments about the addressee's ability rather than the addressee itself. For example, they say 'You have an amazing voice!' to praise the addressee's singing ability by saying 'Really, you are good singer'. 
The table below presents the distribution of the participants' compliments characteristics based on their response in DCT:

Table 7. The Characteristics of the Learners' Compliments

\begin{tabular}{|c|c|c|}
\hline \multirow{2}{*}{ Topic } & \multicolumn{2}{|l|}{ Pattern } \\
\hline & Compliment the Object & Using 'I' as the subject \\
\hline Possession & $\begin{array}{l}\text { 1. That a nice shoes, Michael } \\
\text { 2. Hmm, is that a new bag I see there Ella? } \\
\text { such a nice bag... I wished I can have } \\
\text { some leeway to get a new bag too. } \\
\text { 3. Nice shoes you have there. I also want } \\
\text { something cool like that. where did you } \\
\text { buy it? } \\
\text { 4. Hi, Michael. Do you have new shoes? } \\
\text { What a beautiful shoes you are wearing } \\
\text { 5. Wow, your cellphone is very good, } \\
\text { hopefully with that cellphone can make } \\
\text { you more enthusiastic to learn. }\end{array}$ & $\begin{array}{l}\text { 1. I like your shoes, } \\
\text { very beautiful. } \\
\text { 2. I love your cell } \\
\text { phone, very smart. }\end{array}$ \\
\hline \multirow[t]{2}{*}{ Appearance } & Compliment the Addressee & Using 'I' as the subject \\
\hline & $\begin{array}{l}\text { 1. You look beautiful with that hair style! } \\
\text { 2. You look nice with your suit, Aldi } \\
\text { 3. You dressed well Jeff, it's really suits on } \\
\text { you } \\
\text { 4. What a nice clothes, did you plan to hang } \\
\text { out after this? } \\
\text { 5. Wow, you really look the part there. You } \\
\text { can definitely get the job if you keep up } \\
\text { that appearance. }\end{array}$ & $\begin{array}{l}\text { 1. I like your hair style ! } \\
\text { 2. I love your new } \\
\text { hairstyle! Short hair } \\
\text { really suits you! }\end{array}$ \\
\hline Skill/Ability & The Addressee's Ability & $\begin{array}{c}\text { Compliment the } \\
\text { Addressee }\end{array}$ \\
\hline & $\begin{array}{l}\text { 1. You have an amazing voice! } \\
\text { 2. Such a stunning voice, since when do you } \\
\text { train your voice like that? } \\
\text { 3. Good job, my friend. I know it very well } \\
\text { that you can get such high score. } \\
\text { 4. Your explanation so easy to understand.. I } \\
\text { can't believe it } \\
\text { 5. Wanda, your singing was just so soothing } \\
\text { I could listen to it all day long. }\end{array}$ & $\begin{array}{l}\text { 1. Really, you are good } \\
\text { singer. } \\
\text { 2. You are smart, } \\
\text { Farhan! }\end{array}$ \\
\hline
\end{tabular}


The influence of participants' L1 was also found in the production of compliments. For example, 'Such a stunning voice, since when do you train your voice like that?' that uses 'since when' to ask how long the addressee has been training his/her voice so he/she can sing nicely. 'since when' is a literal translation of bahasa Indonesia for 'sejak kapan' but it is not appropriate to use in English. The participants also like to say the addressee's name in their compliment that is commonly found in daily conversation in Indonesia 'Hmm, is that a new bag I see there Ella? such a nice bag... I wished I can have some leeway to get a new bag too.' In this example, the use of the word 'can' that is supposed to be 'could' can be the result of the influence of students' L1 that Indonesia does not use tenses in conversation. Another example is 'Wow, your cellphone is very good, hopefully with that cellphone can make you more enthusiastic to learn.' The wish expression in 'hopefully with that cellphone can make you more enthusiastic to learn' is commonly said to someone that got something new so they can be better in their study.

\section{B. Strategies used based on each situation given}

\section{Topic 1: Possession}

The following table presents the distribution of compliments strategy used by the students for the topic of possession.

Table 8. Compliment strategies for the topic of possession

\begin{tabular}{|c|c|c|c|c|c|}
\hline \multirow{2}{*}{ No. } & \multirow{2}{*}{ Compliment Strategies } & \multicolumn{2}{|c|}{ Situation } & \multicolumn{2}{|c|}{ Frequencies } \\
\hline & & 1 & 4 & 7 & \\
\hline 1. & Explicit (Single) & 23 & 27 & 29 & 79 \\
\hline 2. & Explicit - Information Question & 3 & 7 & 6 & 16 \\
\hline 3. & Explicit - Explanation & 6 & 1 & 4 & 11 \\
\hline 8. & Explicit - Request & 1 & - & - & 1 \\
\hline 9. & Pre-compliment - Explicit & 1 & - & - & 1 \\
\hline 10. & Explicit - Wish Expression & 1 & 2 & - & 3 \\
\hline 11. & Pre-Compliment - Explicit - Request & 1 & - & - & 1 \\
\hline 12. & $\begin{array}{l}\text { Explicit - Information Question - Wish } \\
\text { Expression }\end{array}$ & - & 1 & 1 & 2 \\
\hline 13. & $\begin{array}{l}\text { Explicit - Information Question - Future } \\
\text { Reference }\end{array}$ & - & 1 & - & 1 \\
\hline 14. & Non-Compliment & 4 & - & - & 4 \\
\hline & TOTAL & 39 & 39 & 39 & 117 \\
\hline
\end{tabular}

On the topic of possession, the students mostly used a single explicit strategy and followed by the combination of explicit - explanation and explicit - information questions. 


\section{Topic 2: Appearance}

The following table presents the distribution of compliments strategy produced by the students for the topic of someone's appearance.

Table 9. Compliment strategies used on the topic of appearance

\begin{tabular}{|c|c|c|c|c|c|}
\hline \multirow{2}{*}{ No. } & \multirow{2}{*}{ Compliment Strategies } & \multicolumn{3}{|c|}{ Situation } & \multirow{2}{*}{ Frequencies } \\
\hline & & 2 & 5 & 8 & \\
\hline 1. & Explicit (Single) & 30 & 34 & 30 & 94 \\
\hline 2. & Explicit - Explanation & - & 2 & 3 & 5 \\
\hline 3. & Explicit - Information Question & - & 3 & 4 & 7 \\
\hline 4. & Explicit - Future Reference & 2 & - & - & 2 \\
\hline 5. & Pre-Compliment - Explicit & - & - & 1 & 1 \\
\hline 6. & Explicit - Wish Expression & 5 & - & - & 5 \\
\hline 7. & $\begin{array}{l}\text { Explicit - Explanation - Information } \\
\text { Question }\end{array}$ & - & - & 1 & 1 \\
\hline 8. & Pre-Compliment - Implicit & 1 & - & - & 1 \\
\hline 9. & Non-Compliment & 1 & - & - & 1 \\
\hline & TOTAL & 39 & 39 & 39 & 117 \\
\hline
\end{tabular}

On the topic of appearance, the students also frequently used single explicit, followed by the combination of explicit - information question, explicit - explanation and explicit wish expression.

\section{Topic 3: Skill or Ability}

The following table presents the distribution of compliments strategy used by the students for the topic of someone's appearance.

Table 10. Compliment strategies used on the topic of skill or ability

\begin{tabular}{llcccc}
\hline \multirow{2}{*}{ No. Compliment Strategies } & \multicolumn{3}{c}{ Situation } & \multirow{2}{*}{ Frequencies } \\
\cline { 3 - 5 } & & $\mathbf{3}$ & $\mathbf{6}$ & $\mathbf{9}$ & \\
\hline 1. & Explicit (Single) & 31 & 24 & 25 & 80 \\
2. & Explicit - Explanation & 5 & 11 & 6 & 23 \\
3. & Explicit - Congratulation & - & - & 4 & 4 \\
4. & Explicit - Advice & - & 1 & 1 & 2 \\
5. & Explicit - Request & - & 1 & 1 & 2 \\
6. & Explicit - Wish Expression & - & - & 1 & 1 \\
7. & Explicit - Information Question & 1 & - & - & 1 \\
8. & Explicit - Information Question & - & - & - & 1
\end{tabular}




\begin{tabular}{llcccc} 
9. & Implicit (Single) & 1 & 1 & - & 2 \\
10. & Implicit - Explanation & 1 & - & - & 1 \\
11. & Non-Compliment & - & - & 1 & 1 \\
\hline TOTAL & $\mathbf{3 9}$ & $\mathbf{3 9}$ & $\mathbf{3 9}$ & $\mathbf{1 1 7}$ \\
\hline
\end{tabular}

On the topic of skill or ability, the most used strategy is the single explicit strategy followed by the combination of explicit - explanation and explicit - congratulation. The combinations of explicit - congratulation were found only in situation number 9 that required the students to give a compliment on someone's achievement. The use of congratulation with explicit compliments may be due to the common behaviour in their social culture to praise and congratulate someone's achievement.

\section{DISCUSSION}

The explicit compliment strategy has the highest percentage of the other strategies. The comparison between explicit and implicit compliments is far in both single forms and with the combination. It seems that the students prefer to give direct praise and are open to show their admiration in any situation to the addressee rather than implicitly saying it. The result of the compliment strategy in this research does not appear to be different from Yuan (2002) that explicit compliment is the most used strategy and appears with combination rather than implicit compliment. The findings of this research are also relevant to a study conducted by Alqarni (2020). He also found that unbound semantic formula, especially explicit compliments is the most employed strategy by the Saudi Arabian EFL learners. Similarly, Purnomo (2015) also found that the English Teachers in his research mostly used a 'head act strategy' that directly expresses their compliment as the sign of closeness and solidarity. From several studies conducted, A direct and explicit compliment was found to be the most used strategy for EFL learners or teachers.

The single explicit compliment is an explicit compliment that has no combination with bound semantic formulas or supporting moves. For example, 'You did a good exam', 'Your new style amazed me' and 'Your presentation so great!'. There are 253 data for this strategy that show that the students prefer to express their praise simply and directly in single explicit compliments rather than adding a combination. Besides single explicit compliments, the use of some combinations implies that the learners have creativity in using English to give their compliments, especially in the use of the combination of unbound with more than one bound or supporting moves strategies. Some learners may have a better pragmatic understanding so that they can use more combinations of strategies in giving compliments creatively. In line with this situation, the way the EFL students use the target language to express and interpret particular intentions can be used as an observation to see their pragmatic competence (Purwanti, 2019) 
Based on the topic, the explicit compliment is the most widely used for all topics, especially single explicit compliments. This shows that the topic given does not affect the strategy the student used in giving the compliment. In line with this result, Alqarni (2017) found that on the topic of someone's belonging and appearance, the complimenter mostly used explicit compliment and the dominance of unbound semantic formula found on the topic of academic success.

The characteristic of the overall compliment produced by the EFL learners observed from the topic may be influenced by their L1 in producing in their target language (TL). Wu and Takahasi (2016) describe some distinctive patterns between Chinese native speakers and American native speakers that Chinese native speakers prefer to compliment someone with 'NP is AD' for example 'your bag is very nice' while American native speakers prefer to use ' $I$ ' as the subject such as 'I like/love your...' the same goes to the topic of appearance that the students prefer to compliment the addressee that using ' $I$ ' as the subject. On the topic of skill or ability, the American native speakers prefer to compliment someone's ability for example 'that was a great presentation' or 'you sing so well! I like your voice!' rather than compliment the addressee while Chinese native speakers prefer to compliment the addressee such as 'you're great' or 'you are smart'. The Chinese native speakers also like to include the addressee's name in their compliment.

In this study, some similarities were found. The EFL students in this study mostly produced compliments such as 'your bag is very nice' or 'you look so handsome' for the topic of possession and appearance. Although there was some production of the pattern such as 'I like/love your...' it has a small amount of occurrence compared to the previous pattern. It shows the similarities between Indonesian ELF learners and Chinese EFL learners in giving a compliment to someone's possession and appearance. On the topic of skill or ability, the EFL learners in this study produced compliments more similar to American native speakers. They tend to give compliments on the addressee's ability such as 'your voice is good' rather than saying 'you are a good singer'.

The influence of L1 also can be found in the way the learners express their thought into their TL. For example, they said 'Wow, your cellphone is very good, hopefully with that cellphone can make you more enthusiastic to learn.' These compliments may be affected by their L1 because, in Indonesia, the sentence 'hopefully with that cellphone can make you more enthusiastic to learn' is a common message for ones who get something new to support their study and is a literal translation for 'semoga dengan ponsel itu bisa membuatmu semakin bersemangat untuk belajar'. Another example is 'Such a stunning voice, since when do you train your voice like that?' to ask how long the addressee has been training his/her voice so he/she can sing nicely. 'Since when' is a literal translation from Bahasa Indonesia for 'sejak kapan' but it is inappropriate in English to use. This direct translation may be because "the intermediate students were able to describe their thoughts with more intricate sentence structures and a wider array of vocabulary, resulting in more direct translations and L1 transfer" (Wu and Takahashi, 2016 p.154). Another

\section{International Journal of Educational Best Practices (IJEBP)}

Vol. 5 No. 2 October 2021

ISSN: 2581-0847

DOI: 10.32851/ijebp.v5n2.p132-152 
influence of L1 on the production of compliments is the use of someone's name in the compliments. For example, 'Hmm, is that a new bag I see there Ella? such a nice bag... I wished I can have some leeway to get a new bag too.' or 'Michael, your shoes is so pretty, it suits your clothes well.' The use of the addressee's name indicates their production is still affected by their L1 because in Indonesia, including one's name in giving a compliment is common to use in daily conversation.

\section{CONCLUSION}

Based on the data analysis, it can be concluded that the learners as the complimenter prefer to use explicit compliments in any situation where they were expected to give compliments. It means that they like to show admiration or give a positive evaluation to someone or something directly. Besides a simple direct compliment, they also prefer to add more sentences to support their compliments, such as the explanation where they add some reason and more positive evaluations of the topic being complimented. They also like to ask for more information about what they praise. Implicit compliments, on the other hand, were rarely used because of the gap of their percentage compared to explicit compliments percentage. It is because to produce implicit compliment require a higher level of language skill compared to explicit compliments.

The combination of explicit compliments varies, such as with advice or request or even with more than one bound semantic formula that implies besides complimenting simply, they also like to attach some more expressions with the explicit compliment. The combination of implicit compliments with bound semantic formulas was found not as varied as the combination of explicit compliments and some bound semantic formulas. It indicates that this strategy of giving compliments is not common to use by the learners. In terms of the topics, there is no difference from the strategies used by learners observed based on the topics given. Explicit strategy is the most used strategy by the learners for all the topics, especially single explicit compliments. The influence of the learners' L1 in their production of compliment into their TL can be seen such as using literal translation and including one's name in their compliment.

\section{REFERENCES}

Al-Azzawi, J. N. (2011). Compliments and Positive Politeness Strategies. Journal of the College of Basic Education مجلة كلية التربية الاساسية, 17(71),111-126. ISSN: 18157467(print) 27068536(online). Retrieved from https://www.iasj.net/iasj

Alqarni, S. (2017) A Sociolinguistic Investigation of Compliments and Compliment Responses among Young Saudis. (Masters disertation, Western Sydney University). Western Sydney University. 
Alqarni, S., (2020). A Sociolinguistic Investigation of Compliments and Compliment Responses among Young Saudis. Arab World English Journal (AWEJ) .11(1)

Bruti, S. (2008). Translating Compliments in Subtitle. From Didactas to Ecolingua : An Ongoing Research Project on Translation. (pp. 99 - 110). EUT Edizioni Universitas di Trieste

Dastjerdi, H. V., Farshid, M. (2011) The Role of Input Enhancement in Teaching Compliment. Journal of Teaching and Research, 2(2), 460-466. doi:10.4304/jltr.2.2.460-466

Dirgeyasa, I. Wy. (2015) The Compliment: Its Concept, Function, Common Topics, and Typical Responses in Communication. Proceeding of the Third International Seminar on English Language Teaching. 3(39), 227-232. ISBN: 978-602-17017-75

Farenkia, M.B. (2012) Compliment Strategies and Regional Variation in French: Evidence from Cameroon and Canadian French. International Pragmatics Association. 22(3). 447-476. DOI: 10.1075/prag.22.3.05mul.

García, B.M.J. (2018). Face-enhancing compliments in informal conversations in Valencian Spanish. Borealis - An International Journal of Hispanic Linguistics, 7(1), 147-168. https://doi.org/10.7557/1.7.1.4315

Purwanti, I.T., (2019). Exploring the Effects of Pragmatic Intervention on EFL Students' Production of Refusals: A Qualitative analysis. PROCEEDINGs SEMIRATA 2019: International Seminar \& Annual Meeting, Field of Language, Literature, Arts, and Culture BKS PTN Wilayah Barat.

Wu, H. C \& Takahashi. (2016). Developmental Patterns of Interlanguage Pragmatics in Taiwanese EFL Learners: Compliments and Compliment Responses. The Asian EFL Journal Quarterly. 18(1) http://www.asian-efl-journal.com. ISSN 1738-1460.

Yuan, Y. (2002). Compliment and Compliment Responses in Kunming Chinese. International Pragmatic Association. 12(2). (pp.183-226) doi: 10.1075/prag.12.2.04yua.

Zhang, J. (2013). Compliment and Compliment Responses in Philippines English. GEMA Online Journal of Language Studies. 13(1). ISSN:1657-8021 